\title{
Self-rated Health Among Saudi Women: Association with Morbidity, Lifestyle, and Psychosocial Factors
}

\author{
Hoda Jradi1 ${ }^{1,}$, Zuhaa Alharbi ${ }^{1}$, Yasmeen Mohammad ${ }^{2}$ \\ ${ }^{1}$ King Abdullah International Medical Research Center, King Saud Bin Abdulaziz University for Health Sciences, \\ College of Public Health and Health Informatics, Riyadh 11481, Saudi Arabia \\ ${ }^{2}$ New York University College of Arts and Sciences, New York City, NY, USA
}

\author{
ARTICLE INFO \\ Article History \\ Received 7 January 2018 \\ Accepted 9 October 2018 \\ Keywords \\ Self-rated health \\ women \\ well-being \\ lifestyle \\ Saudi Arabia
}

\begin{abstract}
Self-rated health (SRH) is an essential global measure of general health and quality of life, and a predictor of the mortality and morbidity of populations. We assessed the SRH and identified associated factors among women in Riyadh, the capital of Saudi Arabia, using a cross-sectional survey conducted on a sample of women aged 18 years and older. Univariate and multivariate logistic regression analyses were conducted to identify factors that are significantly associated with SRH. Overall, $36.6 \%(n=329)$ of participating women reported poor SRH. Higher body mass index (BMI), physical inactivity, greater number of morbidities, and reporting ill-being/likely depression were significantly associated with poor SRH. The findings from this study suggest that health status, lifestyle factors, and psychosocial conditions are associated with SRH in this population. Focusing on these factors suggests a turning point for public health policies and interventions to improve the health and quality of life of this group of women.
\end{abstract}

(C) 2018 Atlantis Press International B.V. This is an open access article under the CC BY-NC license (http://creativecommons.org/licenses/by-nc/4.0/).

\section{INTRODUCTION}

According to the World Health Organization (WHO), health is more than the absence of disease or infirmity; it is "a complete state of physical, mental, and social well-being" [1]. As such, in order to understand and achieve health, its biological and medical determinants must be addressed in addition to its social and environmental factors. Self-rated health (SRH) is a means by which measurements of health are achieved. It involves the use of a simple question asking individuals to rate their health on a four- or fivepoint scale. The typical wording is "In general, would you say your health is excellent, very good, good, fair, or poor" [2]. SRH has been used in clinical studies as a screening tool for general health assessment and as a predictor of morbidity, mortality, and quality of life [1,3-5]. Additionally, SRH has been used in population-based studies due to its ability to predict future health and healthcare services utilization [6-8]. Socioeconomic, morbidityrelated, lifestyle and psychosocial factors constitute the determinants of SRH in different populations [9-11]. Identifying SRH determinants in diverse populations (different countries, regions, genders, ethnic groups, or age groups) has many public health advantages. Primarily, many of the characteristics displayed by the group under investigation (in particular among women and other vulnerable groups) would be recognized by public health practitioners for the purpose of formulating policy and implementing better public health services. Also, disentangling SRH into its major components enables the public health practitioner to

*Corresponding author.Emails: Jradih@KSAU-HS.EDU.SA;Jradiho@NGHA.MED.SA; Hoda.Jradi@gmail.com design more targeted interventions at all levels for the population under investigation. Women are not a well-studied group in Saudi Arabia; particularly when it comes to the context of their subjective cognitive satisfaction with their own health. No studies in Saudi Arabia have investigated the independent effect of material and psychosocial conditions, as well as lifestyle factors, on SRH. It is important to investigate the roles of these factors due to their implications for policy and intervention development in the community and the health system. The aim of this study was to investigate the association between socioeconomic status, material and psychosocial conditions, lifestyle factors, morbidities, and SRH among women in Saudi Arabia with a broad range of variables covering these factors.

\section{MATERIALS AND METHODS}

Self-rated health and associated factors were investigated in a Saudi population sample of women aged 18-70 years residing in the city of Riyadh, Saudi Arabia. The data were collected from July to September 2015 using an interviewer-administered questionnaire. The instrument used was constructed based on thorough review of the literature regarding factors that have been reported to have an impact on SRH among women in different populations. The validity of the content of the instrument was ascertained by involving two social workers and a professor specializing in women's health in the review of the questions, and their input regarding the adequacy of the terms and concepts used was documented. The questionnaire was in the Arabic language, and all questions were checked for face validity, clarity of the 
language used, comprehension, and time management by testing it on a group of 30 women. Modifications were made to the questionnaire as suggested by the group of women. The reliability of the instrument was checked by administering the questionnaire twice to the same group of women $(n=25)$ and within a 1 -week interval between the two interviews.

The sampling included stratification of the city into five regions (northern, eastern, western, central, and southern), random selection of two large shopping centers in each region, random selection of days of the week and hours of the day for data collection, and random selection of women entering the selected shopping facilities. Shopping malls are a major destination for women of all ages and all socioeconomic backgrounds in the city of Riyadh. A total of 950 women were asked to participate in the study, and 900 gave consent to be interviewed for an overall response rate of $95 \%$.

\subsection{Socioeconomic Status}

The age of the participants was grouped into four categories: 18-28 years, 29-39 years, 40-49 years, and $\geq 50$ years old. Educational level was categorized into five classes: illiterate, elementary school, middle school, high school, and college or higher. Employment status was derived from a survey question regarding whether the participant was employed, unemployed, a student, or retired. Economic status was assessed by classifying income into four categories in Saudi Riyals ( 1 USD $\approx 3.7$ SR): $\leq 5000,5100-10,000$, $10,100-15,000,>15,000$. The participants were also asked about their marital status.

\subsection{Lifestyle Factors}

The participants' body mass index (BMI) was calculated from self-reported weight and height as $\mathrm{kg} / \mathrm{m}^{2}$. The participants were classified according to WHO recommendations into three categories: underweight $\left(<18.5 \mathrm{~kg} / \mathrm{m}^{2}\right)$, normal $\left(<25 \mathrm{~kg} / \mathrm{m}^{2}\right)$, overweight $\left(25-29.9 \mathrm{~kg} / \mathrm{m}^{2}\right)$, and obese $\left(\geq 30 \mathrm{~kg} / \mathrm{m}^{2}\right)$. The level of physical activity was assessed by asking the following question: "How many days per week do you exercise (walking, bicycling, or other type of exercise) for 30 minutes or more?" The responses were categorized to reflect physically active (exercising three times a week for 30 minutes or more) or not physically active women. Smoking behavior was assessed by the question: "What is your smoking status?" with the answer options "I am a currently a smoker," "I am a former smoker," and "I never smoked."

\subsection{Physical Environment}

The physical environment was described by asking the participants: "Do you have disturbance in or around your place of residence or work (among participants who were employed) from the following sources?" The listed sources were noise or exhaust from surrounding streets or nearby factories, smelly fumes or gases, or other disturbances with the answer options of "Yes" or "No." The responses were then summarized to reflect a good or poor physical environment.

\subsection{Physical Health and Psychosocial Health}

The health status was assessed by the following question: "Do you currently have a disease/health condition that requires treatment?" The response choices were: no morbidities, one morbidity, and comorbidity for reporting two or more diseases. Well-being as a measure of psychosocial health was also elicited separately by administering the Arabic version of the five-item WHO (WHO-5) well-being index [12]. The WHO-5 well-being index has been validated, translated into many languages, and used in studies in different countries [13]. Responses to the five questions were recorded from 0 (never) to 5 (always) with a possible range of scores between 0 and 25 . Scores were converted to percentages and an obtained percent score $\leq 50$ was indicative of low psychological well-being $[14,15]$.

\subsection{Statistical Analyses}

Analyses were performed using the STATA statistical software (version 13; College Station, TX, USA). Descriptive statistics as the means and frequencies were calculated for all study variables where applicable. The differences in the categories of SRH across study variables (demographic characteristics, socioeconomic status, physical environment, lifestyle factors, and health status) were assessed. The $t$-test was used for continuous variables and the chi-square test for categorical variables to examine significant differences in the parameters.

Univariate and multivariate logistic regression analyses were performed with SRH as the dependent variable to examine the simultaneous effects of the studied factors on SRH. The odds ratios (OR) and $95 \%$ confidence intervals (CI) of good SRH compared with poor SRH were calculated for a range of study variables. First, all the demographic variables that showed significance in the univariate analysis were entered into the logistic model. Next, the variables related to the physical environment were introduced, and thereafter, lifestyle factors. Finally, the number of morbidities and the measure of well-being as covariates were included. Stepwise backward elimination of nonsignificant variables was applied (significance level set at $p<0.05$ ). A total of 900 participants with full data for all variables were considered.

\section{RESULTS}

Table 1 presents the number of participants in the different age groups (mean age was 29.3 years; standard deviation \pm 9.7 ) and the frequencies and distribution of the characteristics for the total sample. The majority of the women were high school graduates (46.6\%), single (54.4\%), and employed (44.7\%). The mean BMI was $24.5 \mathrm{~kg} / \mathrm{m}^{2}$. Approximately $47 \%$ of the participants reported being physically inactive and $43.7 \%$ said they lived or worked in an unfavorable physical environment. About $46 \%$ of the surveyed women reported having one or more morbidity, and $41.4 \%$ were likely to have low psychosocial health. The overall prevalence of poor SRH among this sample of women was $36.6 \%$.

Table 2 displays the classification of the participants by SRH. The proportion of poor or good SRH did not vary by age or employment 
Table 1 Characteristics of study participants $(N=900)$

\begin{tabular}{|c|c|c|}
\hline Characteristics & $N$ & Percentage (\%) \\
\hline \multicolumn{3}{|l|}{ Age $(y)(\mu=29.3 ; \mathrm{SD}=9.7)$} \\
\hline $18-28$ & 385 & 42.8 \\
\hline $29-39$ & 233 & 25.9 \\
\hline $40-49$ & 185 & 20.6 \\
\hline$\geq 50$ & 97 & 10.8 \\
\hline \multicolumn{3}{|l|}{ Marital status } \\
\hline Single & 481 & 53.4 \\
\hline Married & 333 & 37 \\
\hline Separated/divorced/widowed & 86 & 9.6 \\
\hline \multicolumn{3}{|l|}{ Educational level } \\
\hline Illiterate & 15 & 1.7 \\
\hline Elementary & 66 & 7.3 \\
\hline Middle school & 50 & 5.6 \\
\hline High school & 419 & 46.6 \\
\hline College or more & 350 & 38.9 \\
\hline \multicolumn{3}{|l|}{ Employment status } \\
\hline Employed & 402 & 44.7 \\
\hline Not employed & 459 & 51 \\
\hline Student & 39 & 4.3 \\
\hline Retired & 2 & 0.2 \\
\hline \multicolumn{3}{|l|}{ Income level (SR) } \\
\hline$\leq 5000$ & 470 & 52.2 \\
\hline $5100-10,000$ & 236 & 26.2 \\
\hline $10,100-15,000$ & 124 & 13.8 \\
\hline$>15,000$ & 70 & 7.8 \\
\hline \multicolumn{3}{|l|}{$\operatorname{BMI}(\mu=24.5)$} \\
\hline Underweight $(\mathrm{BMI}<18.5)$ & 52 & 5.8 \\
\hline Normal weight (BMI 18.5-24.9) & 431 & 47.9 \\
\hline Overweight (BMI 25-29.9) & 279 & 31 \\
\hline Obese $(\mathrm{BMI}>30)$ & 138 & 15.3 \\
\hline \multicolumn{3}{|l|}{ Physical activity } \\
\hline Yes & 481 & 53.4 \\
\hline No & 419 & 46.6 \\
\hline \multicolumn{3}{|l|}{ Smoking status } \\
\hline Current smoker & 45 & 5 \\
\hline Never smoker & 806 & 5.4 \\
\hline Former smoker & 49 & 89.6 \\
\hline \multicolumn{3}{|l|}{ Dietary behavior } \\
\hline Good & 60 & 6.7 \\
\hline Less than good & 840 & 93.3 \\
\hline \multicolumn{3}{|l|}{ Physical environment } \\
\hline Favorable & 507 & 56.3 \\
\hline Unfavorable & 393 & 43.7 \\
\hline \multicolumn{3}{|l|}{ Reported morbidities } \\
\hline 0 & 486 & 54 \\
\hline 1 & 249 & 27.7 \\
\hline 2 & 121 & 13.4 \\
\hline 3 or more & 44 & 4.9 \\
\hline \multicolumn{3}{|l|}{ Psychosocial health } \\
\hline Good & 527 & 58.6 \\
\hline Poor & 373 & 41.4 \\
\hline \multicolumn{3}{|l|}{ Self-rated health } \\
\hline Good & 571 & 63.4 \\
\hline Poor & 329 & 36.6 \\
\hline
\end{tabular}

BMI, body mass index in $\mathrm{kg} / \mathrm{m}^{2}$; SD, standard deviation; SR, Saudi Riyals (1 SR = 0.27 USD).

status, or level of education. The proportion of women with poor SRH was significantly higher among those who were overweight/ obese $(p<0.001)$, physically inactive $(p<0.001)$, worked or lived in an unfavorable environment $(p=0.003)$, and reported having at least one morbidity $(p<0.001)$. Poor scores on the WHO-5 well-being scale were also significantly associated with poor SRH $(p=0.001)$.
Table 2 Comparison of socioeconomic status, physical environment, lifestyle factors, and health status among women with good and poor selfrated heath $(N=900)$

\begin{tabular}{|c|c|c|c|}
\hline \multirow{2}{*}{ Variables } & \multicolumn{2}{|c|}{ Self-rated health } & \multirow{2}{*}{$p$-Value } \\
\hline & Good & Poor & \\
\hline \multicolumn{4}{|l|}{ Age $(y)(\mu=29.3 ; \mathrm{SD}=9.7)$} \\
\hline $18-28$ & 327 & 175 & 0.7 \\
\hline $29-39$ & 161 & 99 & \\
\hline $40-49$ & 57 & 38 & \\
\hline$\geq 50$ & 26 & 17 & \\
\hline \multicolumn{4}{|l|}{ Marital status } \\
\hline Single & 316 & 165 & 0.09 \\
\hline Married & 209 & 124 & \\
\hline Separated/divorced/widowed & 46 & 40 & \\
\hline \multicolumn{4}{|l|}{ Educational level } \\
\hline Illiterate & 10 & 5 & 0.9 \\
\hline Elementary & 41 & 25 & \\
\hline Middle school & 33 & 17 & \\
\hline High school & 260 & 15 & \\
\hline College or more & 227 & 123 & \\
\hline \multicolumn{4}{|l|}{ Employment status } \\
\hline Employed & 308 & 151 & 0.06 \\
\hline Not employed & 240 & 160 & \\
\hline Student & 21 & 18 & \\
\hline Retired & 2 & 0 & \\
\hline \multicolumn{4}{|l|}{ Income level (SR) } \\
\hline$\leq 5000$ & 293 & 177 & 0.8 \\
\hline $5100-10,000$ & 155 & 81 & \\
\hline $10,100-15,000$ & 80 & 44 & \\
\hline$>15,000$ & 43 & 27 & \\
\hline \multicolumn{4}{|l|}{ Body mass index $(N=741)$} \\
\hline Normal weight (BMI 18.5-24.9) & 369 & 114 & $<0.001^{*}$ \\
\hline Overweight (BMI 25-29.9) & 128 & 151 & \\
\hline Obese $(\mathrm{BMI}>30)$ & 74 & 64 & \\
\hline \multicolumn{4}{|l|}{ Physical activity } \\
\hline Yes & 380 & 101 & $<0.001^{*}$ \\
\hline No & 191 & 228 & \\
\hline \multicolumn{4}{|l|}{ Smoking status } \\
\hline Current smoker & 29 & 16 & 0.50 \\
\hline Never smoker & 515 & 291 & \\
\hline Former smoker & 27 & 22 & \\
\hline \multicolumn{4}{|l|}{ Physical environment } \\
\hline Favorable & 343 & 164 & $0.003^{*}$ \\
\hline Unfavorable & 228 & 165 & \\
\hline \multicolumn{4}{|l|}{ Reported morbidities } \\
\hline 0 & 373 & 98 & $<0.001^{*}$ \\
\hline 1 & 162 & 66 & \\
\hline 2 or more & 36 & 39 & \\
\hline \multicolumn{4}{|l|}{ Psychosocial health } \\
\hline Good & 359 & 168 & $0.001^{*}$ \\
\hline Poor & 212 & 161 & \\
\hline
\end{tabular}

Table 3 shows the results of the univariate and multivariate regression analysis for factors associated with SRH. Odds of reporting poor SRH from the univariate regression analysis were the highest for participants with two or more morbidities $(\mathrm{OR}=5.0 ; 95 \% \mathrm{CI}: 3.295-9.968)$ followed by those who reported being physically inactive (OR $=4.5 ; 95 \% \mathrm{CI}: 3.460-5.051)$. The odds of reporting poor SRH among those with high BMI was approximately three times that of reporting a normal BMI (95\% CI: 2.452-4.792). Living or working in an unfavorable physical environment increased the risk of poor SRH by 1.5 -fold 
(95\% CI: 1.092-1.973). In addition, the risk of poor SRH increased by 1.6 -fold (95\% CI: $1.200-2.086)$ for reporting poor psychosocial health.

Multivariate logistic regressions were conducted to examine the independent effect of all factors that showed a significant association with SRH among this group of women. As shown in Table 3, in the final adjusted model, higher BMI, physical inactivity, greater number of morbidities, and reporting ill-being/likely depression were significantly associated with poor SRH. The risk of poor SRH did not reach statistical significance for those residing or working in an unfavorable physical environment when adjusting for all other factors. The final model showed a good fit (Hosmer-Lemeshow goodness-of-fit test; $p \geq 0.05$ ).

\section{DISCUSSION}

In this study, an association was found between SRH and BMI, physical activity, number of morbidities, and general psychosocial health adjusting for all other factors. Unadjusted binary logistic regression analysis reflected the influence of the physical environment on SRH as an additional significant factor among this group of women. Being overweight and obese, as well as being physical inactive, were among the lifestyle factors that were shown to be independently associated with SRH. Similarly to many published international studies [9,16-18] overweight and obese women in this study were less likely to rate their health as good. Also, despite some evidence from the literature that being overweight and obese are more prevalent in the lower socioeconomic groups [16], results from this study showed that socioeconomic status and other social determinants did not modify the association between SRH and high BMI. This is an indication that the stigma of obesity has become a global phenomenon among many populations and across social classes [19]. In particular, women are more likely to consider being overweight and obese a major health concern $[19,20]$ that may contribute to the way they rate their health [21]. In accordance with previous studies from Sweden and the USA $[10,22]$, findings in this study presented evidence that a high level of physical activity is independently associated with good SRH. The literature contains overwhelming evidence that physical activity is beneficial for all body functions and psychological conditions [23].

In addition to BMI and physical activity, this study suggests that morbidities are significant independent predictors of SRH. Many studies in the literature have reported on the impact of morbidities on SRH. For example, studies conducted among the general population reported that chronic conditions can have a negative impact on health perceptions $[9,24]$, and quality of life [9,25]. Also, similar to other studies in the USA and England, the odds of reporting poor SRH increased with the number of reported health conditions $[5,26]$. Women reporting two or more conditions were approximately twice as likely to report poor SRH then women with one morbidity, and the odds were five times that of reporting no morbidities. Identifying these conditions may be particularly important, since poorer SRH has been previously shown to be associated with cardiovascular diseases [26] and with a high level of anxiety disorder [27]. This implies that interventions targeted toward identified specific morbidities would have the highest impact on poor SRH among this population of women. The perceived health status by this group of women may reflect a disease burden that deserves further investigation. It is important to mention that the information on the number of morbidities was self-reported in this study. The reporting may not be specific because it is unknown what the exact diseases and symptoms are that this population suffers from, and how they are connected.

The findings in this study showed a significant association between self-reported psychological well-being and SRH, suggesting that in agreement with other studies, poor SRH is common among participants reporting low psychological health [9].

The strength of this study is that it covers a wide range of variables and is based on a relatively large sample of women from

Table 3 Predictors of poor self-rated health in a sample of Saudi women $(N=900)$

\begin{tabular}{|c|c|c|c|c|c|c|}
\hline \multirow{2}{*}{ Variables } & \multicolumn{3}{|c|}{ Unadjusted } & \multicolumn{3}{|c|}{ Adjusted } \\
\hline & OR & $95 \% \mathrm{CI}$ & $p$-Value & OR & $95 \% \mathrm{CI}$ & $p$-Value \\
\hline \multicolumn{7}{|l|}{ Body mass index } \\
\hline Normal weight & 1.0 (ref) & & & $1.0(\mathrm{ref})$ & & \\
\hline Overweight/obese & 3.3 & $2.457-4.792$ & $<0.001^{*}$ & 2.5 & $1.949-4.670$ & $<0.001^{*}$ \\
\hline \multicolumn{7}{|l|}{ Physical activity } \\
\hline Yes & $1.0(\mathrm{ref})$ & & & 1.0 (ref) & & \\
\hline No & 4.5 & $3.460-5.051$ & $<0.001^{*}$ & 2.8 & $2.071-3.871$ & $<0.001^{*}$ \\
\hline \multicolumn{7}{|l|}{ Physical environment } \\
\hline Favorable & 1.0 (ref) & & & $1.0(\mathrm{ref})$ & & \\
\hline Unfavorable & 1.5 & $1.092-1.973$ & $0.003^{*}$ & 1.1 & $0.864-1.274$ & 0.06 \\
\hline \multicolumn{7}{|l|}{ Reported morbidity } \\
\hline 0 & $1.0(\mathrm{ref})$ & & & & & \\
\hline 1 & 3.3 & $2.151-4.987$ & $<0.001^{*}$ & 3.3 & $1.972-5.00$ & $<0.001^{*}$ \\
\hline 2 or more & 5.0 & $3.295-9.968$ & $<0.001^{*}$ & 5.0 & $3.279-10.009$ & $<0.001^{*}$ \\
\hline \multicolumn{7}{|l|}{ Psychosocial health } \\
\hline Good & $1.0(\mathrm{ref})$ & & & 1.0 (ref) & & \\
\hline Poor & 1.6 & $1.200-2.186$ & $0.001^{*}$ & 1.4 & $1.087-1.890$ & $0.03^{*}$ \\
\hline
\end{tabular}

"Significant at $\alpha=0.05$; CI, confidence interval; OR, odds ratio. 
18 to 70 years of age. There have been no previous studies in Saudi Arabia on SRH among women or men.

The limitations of this study are linked to the fact that the study factors were self-reported and may be subject to recall bias. However, it should be noted that the survey went through a validity and reliability check in this population before use to collect information, and that self-reporting is the only way to collect such information from this population of women. Moreover, this study was cross-sectional, and temporality and causality cannot be investigated. It is worth mentioning that data collection from the general population of women in Saudi Arabia is challenging due to the religious, cultural, and social restriction. Women in Saudi Arabia are most likely to be encountered in shopping malls and the sampling method applied was the most appropriate to ensure data collection. Also, women over the age of 50 years are rarely encountered except in clinics and private social occasions; clarifying why the number of participants over the age of 50 years was less than the other age categories. The response rate was relatively high in this study and the highest number of respondents was found to belong to the younger age group and to more often be single. It is therefore likely that this younger age group is more likely to rate their health better than others. Also, in a future study, it would be important to enroll more women above the age of 50 years in order to assess the possible differences between the age groups. In conclusion, even though high BMI, physical inactivity, and poor psychological health were associated with poor SRH, the number of morbidities they suffered from contributed more to the total burden of poor $\mathrm{SRH}$ in this population of women because of high prevalence. It is recommended to conduct prospective studies to further investigate the association between the number of morbidities, types and associated disabilities, and the role they play in SRH. The predictors of $\mathrm{SRH}$ in this population of women may pose a new turning point for SRH research and for public health policies and interventions in Saudi Arabia.

\section{CONFLICTS OF INTEREST}

None declared.

\section{REFERENCES}

[1] Freedman DS, Berenson GS. Tracking of BMI z scores for severe obesity. Pediatrics 2017;140;e20171072.

[2] Bombak AE. Self-rated health and public health: a critical perspective. Front Public Health 2013;1;15.

[3] Månsson NO, Råstam L. Self-rated health as a predictor of disability pension and death - a prospective study of middle-aged men. Scand J Public Health 2001;29;151-8.

[4] Burström B, Fredlund P. Self rated health: is it as good a predictor of subsequent mortality among adults in lower as well as in higher social classes? J Epidemiol Community Health 2001;55;836-40.

[5] Latham K, Peek CW. Self-rated health and morbidity onset among late midlife US adults. J Gerontol B Psychol Sci Soc Sci 2013;68;107-16.

[6] Su D, Richardson C, Wen M, Pagán JA. Cross-border utilization of health care: evidence from a population-based study in south Texas. Health Serv Res 2011;46;859-76.
[7] Pappa E, Niakas D. Assessment of health care needs and utilization in a mixed public-private system: the case of the Athens area. BMC Health Serv Res 2006;6;146.

[8] DeSalvo KB, Fan VS, McDonell MB, Fihn SD. Predicting mortality and healthcare utilization with a single question. Health Serv Res 2005;40;1234-46.

[9] Molarius A, Berglund K, Eriksson C, Lambe M, Nordström E, Eriksson HG, et al. Socioeconomic conditions, lifestyle factors, and self-rated health among men and women in Sweden. Eur J Public Health 2007;17;125-33.

[10] Södergren M, Sundquist J, Johansson SE, Sundquist K. Physical activity, exercise and self-rated health: a population-based study from Sweden. BMC Public Health 2008;8;352.

[11] Meireles AL, Xavier CC, de Souza Andrade AC, Proietti FA, Caiaffa WT. Self-rated health among urban adolescents: the roles of age, gender, and their associated factors. PLoS One 2015;10;e0132254.

[12] Sibai AM, Chaaya M, Tohme RA, Mahfoud Z, Al-Amin H. Validation of the Arabic version of the 5-item WHO well being index in elderly population. Int J Geriatr Psychiatry 2009;24;106-7.

[13] Topp CW, Østergaard SD, Søndergaard S, Bech P. The WHO-5 Well-Being Index: a systematic review of the literature. Psychother Psychosom 2015;84;167-76.

[14] Peyrot M, Rubin RR, Lauritzen T, Snoek FJ, Matthews DR, Skovlund SE. Psychosocial problems and barriers to improved diabetes management: results of the Cross-National Diabetes Attitudes, Wishes and Needs (DAWN) Study. Diabet Med 2005;22;1379-85.

[15] Heun R, Bonsignore M, Barkow K, Jessen F. Validity of the fiveitem WHO Well-Being Index (WHO-5) in an elderly population. Eur Arch Psychiatry Clin Neurosci 2001;251 Suppl 2;II27-II31.

[16] Krause L, Lampert T. Relation between overweight/obesity and self-rated health among adolescents in Germany. Do socioeconomic status and type of school have an impact on that relation? Int J Environ Res Public Health 2015;12;2262-76.

[17] Bethea TN, Lopez RP, Cozier YC, White LF, McClean MD. The relationship between rural status, individual characteristics, and self-rated health in the Behavioral Risk Factor Surveillance System. J Rural Health 2012;28;327-38.

[18] Laaksonen M, Sarlio-Lähteenkorva S, Leino-Arjas P, Martikainen P, Lahelma E. Body weight and health status: importance of socioeconomic position and working conditions. Obes Res 2005;13;2169-77.

[19] Wang A, Arah OA. Body mass index and poor self-rated health in 49 low-income and middle-income countries, by sex, 2002-2004. Prev Chronic Dis 2015;12;E133.

[20] Lemon SC, Rosal MC, Zapka J, Borg A, Andersen V. Contributions of weight perceptions to weight loss attempts: differences by body mass index and gender. Body Image 2009;6;90-6.

[21] Badawi G, Gariépy G, Pagé V, Schmitz N. Indicators of self-rated health in the Canadian population with diabetes. Diabet Med 2012;29;1021-8.

[22] Tsai J, Ford ES, Li C, Zhao G, Pearson WS, Balluz LS. Multiple healthy behaviors and optimal self-rated health: findings from the 2007 Behavioral Risk Factor Surveillance System Survey. Prev Med 2010;51;268-74.

[23] Warburton DE, Nicol CW, Bredin SS. Health benefits of physical activity: the evidence. CMAJ 2006;174;801-9.

[24] Molarius A, Janson S. Self-rated health, chronic diseases, and symptoms among middle-aged and elderly men and women. J Clin Epidemiol 2002;55;364-70. 
[25] Marmot MG, Fuhrer R, Ettner SL, Marks NF, Bumpass LL, Ryff CD. Contribution of psychosocial factors to socioeconomic differences in health. Milbank Q 1998;76;403-48.

[26] Mavaddat N, Valderas JM, van der Linde R, Khaw KT, Kinmonth AL. Association of self-rated health with multimorbidity, chronic disease and psychosocial factors in a large middle-aged and older cohort from general practice: a cross-sectional study. BMC Fam Pract 2014;15; 185.

[27] Gafarov VV, Panov DO, Gromova EA, Gagulin IV, Gafarova AV. Trait anxiety, awareness, health attitudes and 16-year hazard ratio of acute cardiovascular disease in open female population in Russia. Int J Med Sci 2014;4;30-4. 